\title{
ABORDAGEM DA SEXUALIDADE NAS FORMAÇ̃̃ES CONTINUADAS DE PROFESSORES E PROFESSORAS DA REDE BÁSICA DE ENSINO
}

\author{
SEXUALITY APPROACH IN CONTINUED FORMATIONS TO TEACHERS IN THE BASIC EDUCATION SYSTEM
}

\section{RESUMO}

Este estudo analisou e quantificou os cursos de formação continuada com a temática Sexualidade ofertados para professores e professoras da rede básica de ensino do município de Cascavel - PR, no período de 2006 e 2016. As coletas de dados foram realizadas junto ao Núcleo Regional de Educação (NRE), a Secretaria Municipal de Educação (SEMED) e a Universidade Estadual do Oeste do Paraná (Unioeste). Os resultados apontaram para uma carência no quantitativo de formações continuadas ofertadas no município e evidenciou a importância e necessidade destas para o estudo e formação sobre a temática sexualidade. Este estudo corroborou com resultados de outros estudos no que tange a importância e contribuição das formações continuadas para ampliação da abordagem da sexualidade na escola e evidenciou que é por meio de formações iniciais e continuadas que professores e professoras adquirem conhecimentose (in)formações sobre sexualidade possibilitandoassima incorporação destas em sua prática pedagógica.

Palavras-chave: Educação Sexual. Professores. Escola. Formação continuada.

\begin{abstract}
This study analyzed and quantified continued formation courses on the subject of sexuality offered to teachers in the basic education system of Cascavel, PR from 2006 to 2016. The data were collected at the Núcleo Regional de Educação (NRE), the Secretaria Municipal de Educação (SEMED) and the Universidade Estadual do Oeste do Paraná (Unioeste). The results pointed to a lack of quantitative training in continued formation in the city and highlighted the importance and necessity of these approaches for studies and training on the topic of sexuality for teachers. This study corroborated the results of others regarding the importance and contribution of continued formation to broaden the approaches for sexual education in schools. Our data also showed that through initial and continued formation, teachers acquire knowledge and information about sexuality that enable the incorporation of these ideas into pedagogical practices.
\end{abstract}

Keywords: Sexual Education. Teachers. School. Continued formation.

Izana S. Brol

Universidade Estadual do Oeste do Paraná (UNIOESTE). E-mail: izanabrol@gmail.com

Andréa C. Martelli

Universidade Estadual do Oeste do Paraná (UNIOESTE). E-mail: andreamartelli72@hotmail.com 


\section{Introdução}

Para grande parte da população mundial e a maioria dos dicionários, a sexualidade está reduzida a questões biológicas e a características inatas ao ser humano. De acordo com essa visão e definição, a sexualidade está associada somente ao ato sexual, aos órgãos genitais e ao masculino e feminino (Macedo et al., 2013). Por receber esse tratamento, a sexualidade é reduzida a uma análise biológica, tratando somente de aspectos relacionados à reprodução, aos aparelhos reprodutivos masculinos e femininos, a gravidez e as doenças sexualmente transmissíveis (Jesus, 2007). Dessa forma, a sexualidade recebe um tratamento médico-higienista e permanece cercada de dogmas e preceitos religiosos. No senso comum, o nosso corpo nos define e, portanto, não faz sentido pensar e debater sexualidade no âmbito social, histórico e político (Louro et al., 200o).

Por estar permeada de culpas, medos, tabus, mitos, crenças e repressões, a discussão sobre sexualidade é muitas vezes evitada ou realizada com discrição e certo constrangimento (Louro, 2001). Esses diversos preconceitos e receios despertam curiosidade e geram dúvidas em crianças, adolescentes e adultos. Para desmistificar e minimizar os preconceitos em torno da sexualidade é preciso compreender os aspectos que a englobam, e assim, compreender que ela envolve questões culturais como rituais, linguagens, fantasias, representações, símbolos e convenções (Louro, 2001). Logo, a sexualidade se manifesta de diversas e diferentes formas, e necessita ser compreendida e respeitada por todos em todos os momentos da vida.

A sexualidade exerce efeitos sobre a saúde física e mental dos indivíduos (Fagundes, 2014). Nesse sentido, ela é mais do que o ato sexual e questões biológicas, está associada a aspectos históricos, culturais e pessoais, e cada sujeito vai apresentar uma forma singular de expressar a sua sexualidade. Portanto, não existe o correto ou incorreto, mas diferentes formas de vivê-la (Jesus, 2007).

Presente em nossa vida, do nascimento a velhice, estamos descobrindo e aprendendo sobre sexualidade o tempo todo e em todo lugar, seja em casa, no grupo de amigos, na escola, igreja, trabalho, ou seja, nos mais diversos espaços sociais. Segundo Furlani (2009), os efeitos das manifestações da sexualidade estão em crianças, jovens e adultos e, a partir destes efeitos, é possível compreender conceitos culturais, normas e regras da vida em sociedade.

Para Figueiró (2014: 48), a sexualidade,

(...) é uma dimensão ontológica essencialmente humana, cujas significações e vivências são determinadas pela natureza, pela subjetividade de cada ser humano e, sobretudo, pela cultura, num processo histórico e dialético. A sexualidade não pode, pois, ser restringida à sua dimensão biológica, nem à noção de genitalidade, ou de instinto, ou mesmo libido. Também não pode ser percebida como uma "parte" do corpo. Ela é, pelo contrário, uma energia vital da subjetividade e da cultura, que deve ser compreendida, em 
sua totalidade e globalidade, como uma construção social que é condicionada pelos diferentes momentos históricos, econômicos, políticos e sociais.

A sexualidade no decorrer de sua história foi reprimida e controlada pela igreja, pela medicina, pelo Estado, pela escola e também pela família (Figueiró, 2014), que por meio de "conhecimentos e conceitos arraigados através do tempo e da cultura, nos condicionou a pensar a sexualidade e seus significados de forma estática e inquestionável" (Santos \& Araújo, 2009: 16). Assim, parece difícil encarar de forma natural e espontânea a sexualidade, afinal a Educação Sexual ${ }^{1}$ que muitas vezes recebemos vem de imaginários que a associam única e exclusivamente ao sexo, procriação, doenças sexualmente transmissíveis, vergonhas, tabus, restrições, questões médicas e higiênicas.

Os primeiros estudos sobre sexualidade foram de cunho biológico, visando seus processos e funções - Lamarck (1744-1829), Darwin (1809-1882) e Mendel (1822-1884). O alvo era o sexo, tido como essencial para a reprodução e perpetuação da espécie humana (Bonfim, 2010). A sexualidade era voltada a questões relativas ao dever da mulher para com o homem, a procriação, ao prazer e a questões religiosas. Ainda hoje em nossas escolas presenciamos heranças desses estudos, uma vez que a abordagem predominante é a biologizante do corpo, explicando a sexualidade baseada nas noções de genitalidade, reprodução e prevenção (Bonfim, 2010). Porém, não devemos restringi-la ou limitá-la, uma vez que ela está vinculada a questões históricas, sociais e culturais, envolve desejos, sentimentos, crenças, costumes, experiências e fantasias.

Discutir, refletir e problematizar questões relativas a sexualidade é uma forma de superar paradigmas, preconceitos e desmistificar crenças e mitos. Nesse sentido, a escola representa um espaço importante para abordagem dessa temática, realizando-a por meio de reflexões e discussões científicas. Como instituição, a escola é responsável pela formação de cidadãos e cidadãs críticos e reflexivos, e constitui-se em um meio de emancipação dos indivíduos. A escola é a responsável pela formação de cidadãos e cidadãs críticos eamadurecidos, capazes de transformar valores e normas relacionados à sexualidade e assegurar igualdade e respeito (Figueiró, 2014).

Para trabalhar Educação Sexual na escola é preciso ter como objetivo o incentivo para uma formação social, crítica e criativa dos alunos e alunas (Leão et al., 2010). Assim, é essencial que a escola promova respeito às diferenças, supere tabus e preconceitos e incentive formas de pensar e agir que desmistifiquem a heteronormatividade imposta pela sociedade (Jardim \& Brêtas, 2006). É importante levar os alunos e alunas a pensar sobre sexualidade, a falar sobre o assunto e a

1 Segundo Furlani (2009) e Figueiró (2011), ao usarmos a expressão Educação Sexual, estamos considerando o sujeito como um ser ativo no seu processo de aprendizagem. "Educação Sexual é mais adequado no sentido que considera a pessoa que aprende como sujeito ativo do processo e não apenas um receptor de conhecimentos e/ou orientações" (Figueiró 1996, 291). De acordo com Figueiró (2014, 56), "Orientação Sexual está relacionada ao desejo sexual da pessoa, que pode ser heterossexual, homossexual ou bissexual". Assim, neste trabalho adotaremos a expressão Educação Sexual por considerarmos o aluno e a aluna sujeitos ativos no processo de aprendizagem. 
sanarem as suas curiosidades. Assuntos relacionados a sexualidade passam por todas as relações sociais e fases da vida e são parte constituinte dos sujeitos e suas identidades (Furlani, 2009).

Um espaço comum onde crianças e adolescentes esclarecem suas dúvidas, medos e inquietações sobre sexualidade é a sala de aula. Nesse ambiente eles encontram maior facilidade em se expor e questionar os mais diversos assuntos (Flores, 2004). Além disso, na escola também acontecem manifestações da sexualidade, como curiosidades, vontades e sensações em relação ao corpo e aos colegas. Assim, esse espaço pode propiciar novas práticas sociais e, portanto, as manifestações acerca da sexualidade não deveriam ser ignoradas ou reprimidas, mas sim trabalhadas e vividas com naturalidade.

Para que a sexualidade seja abordada de forma emancipatória, professores e professoras, profissionais de relevada importância neste espaço, necessitam estar preparados e seguros para abordar de forma natural e respeitosa essas questões. Entretanto, pesquisas apontam para o fato destes profissionais carecerem de formação inicial e/ou continuadas que os capacitem para abordar, com conhecimento científico, os diversos questionamentos, curiosidades e dúvidas expressados pelos alunos e alunas. Professores e professoras deveriam problematizar os diversos questionamentos apresentados, com o intuito de contribuir para o rompimento de paradigmas préconcebidos que moldam e restringem os sujeitos (Jesus, 2007).

A maioria dos professores e professoras reproduzem e são influenciados pela Educação Sexual a qual foram sujeitados durante a sua trajetória pessoal, ou seja, uma Educação Sexual muitas vezes baseada em valores culturais, morais e religiosos. A possibilidade desta educação ter sido recebida, em geral, de forma não emancipatória, crítica e reflexiva, faz com que a maioria desses profissionais não se sinta preparado para trabalhar a temática com confiança e naturalidade, sem receios, medos e inseguranças (Flores, 2004). Assim, é importante fornecer uma formação que não vise somente a instrumentalização cognitiva, mas que também recrie o modo como lidam com as expressões da sexualidade que emerge no cotidiano escolar (Gesser et al., 2012). Professores e professoras são vistos como modelos por seus alunos e alunas e tudo que estes dizem ou fazem reflete na mente, atitudes e comportamentos destes (Rohden, 2009). Uma vez não estando preparados e/ou só reproduzindo a Educação Sexual recebida, esta pode se tornar repressiva e doutrinária (Guimarães, 1995).

A falta de formação inicial e continuada faz com que os professores e professoras evitem ou abordem de forma superficial a temática, deixando seus alunos e alunas sem esclarecimentos sobre esse assunto (Louro, 2001). A discussão sobre sexualidade é complexa e envolve questões pessoais, sociais e culturais. Essa complexidade tende a aumentar pela falta de material apropriado e profissionais capacitados para trabalhar de forma correta a temática (Jardim \& Brêtas, 2006). A escola, portanto, carece de práticas sobre sexualidade e formações continuadas que promovam informações e debates com seus professores e professoras sobre o assunto.

Neste trabalho, analisamos a importância do estudo da temática sexualidade e/ou Educação Sexual na formação continuada de professores e professoras da 
rede básica de ensino do município de Cascavel - PR, bem como realizamos um levantamento quantitativo das formações continuadas oferecidas pelo Núcleo Regional de Educação (NRE), Secretaria Municipal de Educação (SEMED) e pela Universidade Estadual do Oeste do Paraná (Unioeste), entre 2006 e 2016. Adicionalmente, aplicamos um questionário, a alguns professores e professoras que participaram de alguma das formações continuadas ofertadas, com o intuito de identificar a importância e relevância das formações continuadas nas práticas desses professores e professoras.

\section{Formação continuada e sexualidade}

A discussão sobre a formação de professores e professoras é fundamental, uma vez que seu papel profissional é constituído em um contexto social e político no qual sua formação influenciará a formação que possibilitará aos outros (Gesser et al., 2012). O acesso ao conhecimento científico sobre sexualidade poderá possibilitar aos professores e as professoras colocar em movimento seus imaginários, que na maioria das vezes, são cristalizados por preconceitos e tabus. É necessário desmistificar que a sexualidade está ligada somente a questões referentes aos aspectos biológicos, mas que envolve valores pessoais, históricos e culturais, como ética, moral e sentimentos (Jardim \& Brêtas, 2006).

As formações continuadas (oficinas, palestras, cursos, grupos de estudos, etc.) podem ser um caminho para diminuir a falta de (in)formação de professores e professoras e superar modelos estagnados, pois oportunizam a atualização, capacitação, reciclagem e ampliação de seus conhecimentos sobre sexualidade (Jardim \& Brêtas, 2006). Essa formação deve ser compreendida como reflexão, pesquisa, ação, descoberta, organização, revisão e construção teórica e não como receita pronta para realização de novas práticas ou ensino de novas tecnologias (Gadotti, 2003). Deve ter como meta a melhoria, ampliação e incentivo ao desenvolvimento pessoal e profissional de professoras e professoras (Figueiró, 2006) e, portanto, cursos e programas de formação continuada devem incentivar professores e professoras a se tornarem profissionais reflexivos, motivandoos a analisar seu modo de agir, pensar e, especialmente, revisar suas práticas pedagógicas (Aquino \& Mussi, 2001).

As formações continuadas como fonte e recurso para aquisição de conhecimentos podem ter um planejamento, organização e execução a longo prazo, apoiando e incentivando o desenvolvimento e formação constante e atualizada de professores e professoras, a fim de tornar a sexualidade uma constante em todas as disciplinas. Logo, professores e professoras capacitados para a abordagem da sexualidade, poderão fornecer uma formação mais cidadã para alunos e alunas (Ferrari \& Martelli, 2013). 


\section{Escola: espaço de discussão da sexualidade}

"A escola, como espaço social, não está isenta da abordagem da sexualidade e deve promover reflexões que permitam aos alunos e alunas reconhecer-se como sujeitos de sua sexualidade" (Figueiró, 2014: 19). Professores e professoras são fundamentais nesse processo e necessitam de formação inicial e continuada que possibilitem o conhecimento e domínio do assunto. De acordo com Figueiró (2014: 36), "todos somos educadores sexuais: pais, professores, demais profissionais e a comunidade em geral, estejamos ou não conscientes disso". Quando estamos em contato com uma criança ou adolescente, respondendo ou não a seus questionamentos, estamos educando-os sexualmente e direta ou indiretamente, influenciando na construção de conceitos, ideias e valores.

A Educação Sexual que recebemos em casa ou nos grupos de amigos e/ ou conhecidos por vezes pode ser fragmentada, superficial, preconceituosa e/ou repressora. Dessa forma, há necessidade da escola promover Educação Sexual e, deve para isso, contar com professores e professoras informados, capacitados e seguros para que possam promovê-la, contribuindo para que seus alunos vivam sua sexualidade, de forma saudável, sem preconceitos e emancipatória.

Nosso estudo contou com a participação de dois professores e oito professoras, totalizando dez profissionais. Todos os professores e professoras participaram de formações continuadas na temática em voga, no período de 2006 a 2016, e todos trabalham há mais de seis anos na área da educação. Além disso, identificamos que quatro participantes são graduados/as e seis possuem ou estão cursando alguma pós-graduação (especialização ou mestrado). Os/as profissionais foram unânimes em afirmar que trabalhar sexualidade na escola é importante e de interesse de alunos e alunas, entretanto, a falta de conhecimento e estudo sobre temática gera dúvidas e conflitos. Percebemos que independente da formação inicial e do tempo de serviço na carreira docente, a temática gera dificuldades e receios na grande maioria dos professores e professoras devido a falta de (in) formação sobre a temática. A postura tomada diante do trabalho com a sexualidade não está associada somente aos conteúdos escolares, as técnicas pedagógicas e as prescrições oficiais, está ligado a ordem da pessoalidade e da significação do tema no contexto das trajetórias profissionais (Gesser et al., 2012).

Os professores e as professoras participantes da nossa pesquisa concordaram que a sexualidade é uma temática importante para se trabalhar, e que ela é um assunto de interesse de seus alunos e alunas. Esses dados também são ratificados nos relatos e discussões que acontecem durante os encontros do Grupo de Estudos Sobre Educação e Sexualidade (GEPEX), da Universidade Estadual do Oeste do Paraná. Em outras palavras, é comum professores e professoras apontarem dificuldades na abordagem de assuntos relacionados à sexualidade. Nesses encontros, muitos afirmam não se sentirem seguros ao serem questionados por seus alunos e alunas sobre dúvidas e curiosidades referente a sexualidade e, por vezes, optam por evitar uma abordagem 
mais detalhada e fundamentada, respondendo de forma sucinta ou ignorando o questionamento. Corroborando com nossas proposições, Figueiró (2014) elenca algumas das preocupações e medos dos professores e professoras que ocasionam a não abordagem da temática, como a preocupação com o domínio do conteúdo e das informações, não saber responder aos questionamentos dos alunos, o receio da reação dos pais e qual a linguagem correta a ser utilizada na abordagem.

No tocante às dificuldades no trabalho com a temática em sala de aula, nossa pesquisa apontou diversas justificativas, conforme descrito abaixo,

Professora $\mathbf{A}^{2}$ : O conservadorismo dos pais e familiares, que impõe para os filhos que há apenas sexo binário (macho e fêmea/ homem e mulher), causando maiores atritos na comunidade escolar e perpetuando bullyng e lesbohomotransfobia.

Professora B: Em se tratando de crianças da Educação Infantil e Anos Iniciais do Ensino Fundamental, considero como dificuldade o fato de descobrir quando casos de abusos e/ou violência sexual estão acontecendo, uma vez que crianças nesta faixa etária precisam se sentir seguras com a outra pessoa para contar o que está acontecendo com elas, precisamos realizar sondagens por diversos meios para se descobrir casos de abuso e/ou violência sexual e sempre com muita cautela e sigilo. Sem contar que são situações que reviram com nossos sentimentos, nos deixando abalados emocionalmente, daí a importância de se ter profissionais capacitados para trabalhar com tais situações, seja na escola ou em qualquer outra instituição.

Professora C: Os pré-conceitos da equipe de trabalho, muitos por não compreender criam barreiras dificultando o trabalho.

Professor D: A aceitação da discussão do tema pelas famílias; O medo dos diretores, coordenadores e professores em tratar o tema, primeiro pela falta de conhecimento e segundo pela pressão social que se impõe sobre a escola para não se discutir o tema.

Professora E: As imposições para a abordagem do assunto, a falta de canais para que todos possam explicitar suas opiniões, razões e convicções.

Professor F: A compreensão em relação ao assunto com meus pares.

Professora G: As resistências das famílias não aceitam o trabalho do professor, ignorância, preconceito, falta de conhecimento.

Professora H: Tabus. Falta de conhecimento principalmente por parte dos gestores o que acaba impedindo de ser realizado um

2 Como forma de preservar a identidade dos (as) participantes usaremos letras do alfabeto para marcar as suas respostas. 
trabalho melhor. Uma vez que se fala nesse tema muitos já dizem que não pode falar de sexo na escola.

Professora I: Poucas capacitações relacionadas à temática e a resistência encontrada na família bem como em boa parte da sociedade em se trabalhar essas questões com as crianças.

Professora J: Conversar abertamente sobre o tema, pois ainda é um assunto "proibido".

As dificuldades apontam para conservadorismo das famílias, falta de apoio dos gestores, preconceito dos colegas, falta de conhecimento, pressão social, falta de conhecimento por parte da família e dos gestores, falta de formações continuadas, etc. Todos esses fatores geram insegurança, incertezas e desconforto aos professores e professoras para trabalharem com a temática, que na visão deles, é polêmica e conflituosa e, portanto, necessita do respaldo das autoridades que permeiam seu espaço de trabalho. Somado a estes fatores presentes no ambiente de trabalho, segundo Figueiró (2000), não podemos esquecer os limites ocasionados pela bagagem (experiências) dos professores e professoras e a precariedade dos seus contextos de formação inicial que limitam ainda mais o trabalho relacionado a sexualidade.

Segundo Bonfim (2010) e Figueiró (2014), a dificuldade em desenvolver a Educação Sexual nas escolas, aponta para uma deficiência na formação inicial de professores e professoras. Isso cria fatores que limitam e restringem o trabalho docente diante das manifestações da sexualidade em sala de aula, haja vista que muitas vezes a formação destes são permeadas por imaginários de medos, vergonhas, tabus e dúvidas. É preciso considerar a história pessoal e profissional dos professores e professoras para compreender suas necessidades. Suas histórias influenciam e, por isso, devem ser colocadas em movimento, para que esses possam trabalhar seus limites e dificuldades, melhorando e aprimorando seus conhecimentos.

Conforme exposto acima diversos são os motivos que influenciam a não abordagem ou uma abordagem superficial da sexualidade na escola. Neste sentido, é compreensível a necessidade destes profissionais participarem de formações continuadas sobre a temática, a fim de reduzir as dificuldades que os limitam. A busca por informações, conhecimentos e formação para ampliação do trabalho docente é influenciada por aspectos da vida pessoal e profissional. Professores e professoras apontaram como justificativas para a busca por formação continuada:

Professora A: Interesse pela temática com pessoas com identidades de gêneros diversas, presenciar preconceito e homofobia nas escolas.

Professora B: Melhor conhecer o assunto e assim aprimorar minha prática na escola, enquanto professora na função de coordenação pedagógica. 
Professora C: Sempre pesquisei sobre a temática sexualidade e gênero, e busco constante formação na área, pois acredito ser essencial para a minha formação enquanto professora de educação infantil.

Professor D: Falta de formação específica na área seja na graduação ou continuada.

Professora E: Conhecimento e informação.

Professor F: Interesse pelo assunto e por pesquisar e trabalhar formação continuada nesta temática.

Professora G: Busca de conhecimento, troca de informações, possibilidade de debate.

Professora H: Sempre tive muito interesse e curiosidade no assunto até pelas inúmeras coisas que sempre ouvimos então sempre quis saber mais para conseguir ajudar outras pessoas.

Professora I: A dificuldade de trabalhar essa temática com as crianças e principalmente a de sensibilizar as famílias da necessidade de a mesma ser discutida desde a infância.

Professora J: Interesse em entender as diferenças inerentes aos seres humanos, logo, inerentes ao meu público alvo (alunos do ensino fundamental e médio).

As justificativas apontam para curiosidade, dificuldades em lidar com o tema e falta de conhecimento sobre o assunto, ou seja, há por parte destes desejo e anseio por informações e conhecimentos. Isso evidencia que as formações iniciais ou não privilegiaram ou não abordaram de forma abrangente a temática, e hoje estes/estas profissionais carecem deste conhecimento. Logo, é por meio das formações continuadas que esses terão a oportunidade de adquirir conhecimento e colocar em movimento seus imaginários sobre sexualidade, buscando se capacitar e complementar sua formação para que possam promover uma Educação Sexual emancipatória.

Escola e corpo docente precisam estar preparados para trabalhar com assuntos relacionados a sexualidade, superando metodologias e conteúdos que privilegiem somente aspectos biológicos, e sua associação às disciplinas de ciências ou biologia (Bonfim, 2010). Figueiró (2014), propõe que a Educação Sexual deve ir além de instruções para a redução do índice de gravidez na adolescência ou das doenças sexualmente transmissíveis (DST), mas deve contribuir para o desenvolvimento da personalidade e qualidade de vida do educando. Entretanto, a sexualidade tematizada nas escolas, na maioria das vezes, está sob o enfoque do risco, da promoção da saúde sexual, da prevenção de gravidez e de doenças, sob um viés individualista (Meyer et al., 2009), ou seja, está distante do desenvolvimento da Educação Sexual. 
Professores e professoras necessitam de formações continuadas que abordem os mais diversos assuntos relacionados a sexualidade, capacitando-os em relação a gênero, diversidade sexual, violência sexual, dentre outros. De acordo com as respostas obtidas, por meio de questionário, as formações continuadas das quais estes profissionais participaram privilegiaram uma variedade de assuntos relacionados à temática, conforme expresso pelos professores e professoras abaixo:

Professora A: Identidade de gênero, gênero, sexualidade, como trabalhar sexualidade em sala de aula sem estigmas, como abordar identidade de gênero em sala de aula, diferenciação de gênero biológico e identidade de gênero, o gênero não binário (macho fêmea), Sexualidade é diferente de sexo.

Professora B: O curso foi "Sexualidade infantil e trabalho pedagógico" - com discussões sobre: A discussão a sexualidade: das ciências da saúde às ciências humanas; $\mathrm{O}$ corpo como expressão a nossa sexualidade; Gênero, sexualidade e sexo; Diversidade sexual e escola; Abuso sexual contra crianças e adolescentes.

Professora C: Sexualidade, violência sexual, gênero.

Professor D: A construção da sexualidade; Diferentes concepções de sexualidade; Sexualidade e Gênero; Vivências de sexualidade nos poderes instituídos (família, religião e educação) e possibilidade de transgressões; Manifestações da sexualidade na escola; Abuso sexual contra a criança e o adolescente; Trabalho docente e a sexualidade, construindo alternativas pedagógicas; Relações entre corpos, gênero e sexualidade; As diferentes formas de viver a sexualidade; Diversidade sexual presente nas escolas; Construção de atividades pedagógicas para o trabalho com as manifestações da sexualidade na escola.

Professora E: Sexualidade, identidade de gênero.

Professor F: Sexualidade infantil, Gênero, Identidade de Gênero, formação do professor.

Professora G: Sexualidade, erotização da infância, dinâmicas para o conhecimento do seu próprio corpo, Caixa de Pandora.

Professora H: Abuso infantil. Entre outros que não me recordo.

Professora I: Gênero e sexualidade; Abuso sexual; desfazendo mitos sobre a sexualidade e deficiências; Erotização Infantil; A cultura do consumo e a erotização na infância; Preconceito e gênero; Maternidade; Filmes e documentários relacionados a temática.

Professora J: Sexualidade e gênero na educação, diversidade sexual: diferentes formas de viver a sexualidade. 
Fica evidente que quando falamos de sexualidade não devemos restringi-la a aspectos biológicos e sexuais, mas que ela permeia diversos outros aspectos da vida. Segundo Figueiró (2014), o ensino escolar brasileiro, marcado por uma visão médicobiologista da sexualidade, e por uma visão normativo-institucional, tem manifestado resistência significativa em considerar e acolher a temática sexualidade como parte da educação integral da pessoa. Todavia, trabalhar sexualidade na escola pode estimular a troca de ideias e possibilitar mudanças nas relações sociais, superando machismos, preconceitos e equívocos (Moizés \& Bueno, 2010).

As formações continuadas são uma ferramenta para pensar as manifestações da sexualidade e suas abordagens no espaço escolar, promovendo novas práticas pedagógicas. Pensar em Educação Sexual conforme Bonfim (2010: 37),

(...) é, antes de tudo, uma prática ou ação de transmissão de conhecimentos, representações, valores e práticas, ou seja, é essencialmente uma forma de Educação. Prática educacional é uma questão tanto cultural, quanto histórica e social, e tem seu entendimento marcado pelas mudanças ocorridas no modo de produção basilar da sociedade, envolvendo, além da dimensão biológica, a subjetividade, a afetividade, a ética, o desejo, a religiosidade, entre outras dimensões.

A Educação Sexual está preocupada com o ensino de valores, atitudes e comportamentos dos seres humanos relativos aos corpos, gêneros e a vivência da expressão sexual (Ribeiro \& Magalhães, 2017). Para que o sujeito viva e compreenda sua sexualidade de forma emancipatória, ela precisa ser vista e entendida como parte integrante do mesmo em todas as situações e espaços, inclusive na escola. A escola se caracteriza como local privilegiado e oportuno para abordagem das mais diversas temáticas, dentre elas a sexualidade. É fundamental que a escola reconheça e respeite o direito que alunos e alunas têm de ser educado socialmente, direito de conhecer a si e tudo que estiver relacionado a sexualidade (Brittos et al., 2013).

De acordo com Figueiró (2014), as formações continuadas devem ser um processo sistemático à longo prazo e com supervisão contínua. Eventos pontuais e de curta duração não irão sanar todas as lacunas de anos de falta de informação e formação, apesar destes trazerem contribuições para a formação dos professores e professoras, é preciso pensar a formação continuada como um processo que deve acontecer de forma prolongada, levando os envolvidos a pensar e repensar sua prática pedagógica.

Apesar da importância e necessidade das formações continuadas, encontramos no município de Cascavel-PR, uma defasagem no quantitativo de formações continuadas com enfoque em sexualidade e Educação Sexual. Considerando o recorte de tempo (2006 a 2016), encontramos um total de 32 formações continuadas, onde a maioria foram ofertadas pela Unioeste (Tabela 1). Observa-se outro fator negativo, a continuidade e/ou sequência das formações continuadas, pois elas aparecem de 
formas esparsas. Há uma concentração de formações continuadas em 2014 e um número reduzido nos anos anteriores e subsequentes.

O município de Cascavel conta com mais de dois mil professores e professoras na rede municipal de ensino, de acordo com o Sindicato dos Professores da Rede Pública de Ensino de Cascavel (SIPROVEL). A rede estadual conta com mais de dois mil professores e professoras, de acordo com o site da Secretaria de Educação (SEED). Isso representa um quantitativo de mais de quatro mil professores e professoras no município, considerando professores e professoras da rede municipal e estadual. Portanto, é evidente a necessidade de ampliar o número e a duração das formações continuadas no município, buscando dessa forma, oportunizar ao maior número possível de profissionais uma formação continuada que os capacite sobre as temáticas que envolvem sexualidade, fazendo-os refletirem e repensarem sua prática pedagógica.

Tabela 1: Relação dos cursos ofertados no município de Cascavel - PR (2006 a 2016).

\begin{tabular}{|c|c|c|c|c|}
\hline ANO/LOCAL & UNIOESTE & SEMED & NRE & TOTAL \\
\hline 2006 & 0 & 0 & 0 & 0 \\
\hline 2007 & 2 & 0 & 1 & 3 \\
\hline 2008 & 0 & 0 & 1 & 1 \\
\hline 2009 & 0 & 0 & 1 & 1 \\
\hline 2010 & 2 & 0 & 0 & 2 \\
\hline 2011 & 2 & 3 & 0 & 5 \\
\hline 2012 & 0 & 1 & 0 & 1 \\
\hline 2013 & 4 & 1 & 0 & 5 \\
\hline 2014 & 5 & 4 & 0 & 9 \\
\hline 2015 & 0 & 0 & 3 & 2 \\
\hline 2016 & 2 & 0 & 0 & 32 \\
\hline TOTAL & 17 & 9 & 6 & 3 \\
\hline
\end{tabular}

Fonte: Izana Brol, 2017.

Nas formações continuadas de professores e professoras é importante buscar desmistificar e superar suas crenças, tabus, medos e verdades sobre sexualidade e despertar nos professores e professoras comprometimento e paixão, além do conhecimento e competência técnica (Figueiró, 2014). Segundo os dados coletados, professores e professoras, de forma unânime, acreditam que formação continuada é uma ferramenta para a ampliação de seus conhecimentos sobre sexualidade. Neste sentido, uma prática reflexiva leva ao aperfeiçoamento da prática, bem como ao conhecimento pedagógico de professores e professoras (Figueiró, 2014). É por meio de formações contínuas que estes profissionais se qualificam e ampliam seus conhecimentos e práticas.

Questionamos aos participantes como se sentiam em sua prática pedagógica depois de participarem de formações continuadas sobre sexualidade ou Educação 
Sexual. Os/as participantes afirmaram que se sentiam mais seguros e confiantes para trabalhar o tema em sala de aula e os motivos foram os mais variados possíveis:

Professora A: Maior aceitação por parte de alguns professores sobre a temática, e menos preconceito por parte dos pais.

Professora B: Inúmeras, mais principalmente a mudança no olhar que se passou a ter com pequenos sinais que antes poderiam passar despercebidos e após o curso passei a considerá-los com maior relevância ao ponto de descobrir um caso de abuso infantil e conseguir rapidamente solucionar e livrar a criança da situação.

Professora C: Acredito que a forma como é abordado os assuntos, realizei o trabalho com um grupo de colegas da mesma instituição, e anterior ao curso eu percebia um tabu ao realizar atividades ou responder questões no cotidiano, que após o curso passaram a ser concebidas de outra maneira, foi possível amadurecer profissionalmente e compreender uma nova forma de trazer as questões de sexualidade para sala de aula sem desrespeitar o aluno e a sua periodização.

Professor D: A primeira e principal mudança acontece de dentro para fora, eu mudo enquanto pessoa e isso afeta o meio social no qual estou inserido. A partir dos cursos pude compreender melhor a sexualidade humana, quebrando barreiras e tabus. Isso de certo modo me ajudou a melhorar a minha própria sexualidade me proporcionando melhor qualidade de vida. Na minha atuação enquanto professor, mudei no modo de agir perante a situações de manifestações da sexualidade dentro e fora da escola. Tenho mais segurança em mediar conflitos e situações relacionadas ao tema.

Professora E: Não houve mudanças, precisamos seguir as diretrizes curriculares e resoluções aprovadas.

Professor F: Mais debates e reflexões sobre a temática e o olhar sobre os alunos.

Professora G: Inserir o assunto no planejamento, desmistificar práticas preconceituosas.

Professora H: Eu melhorei muito minha visão para os acontecimentos diários tanto dentro de sala quanto em casa. Estou sempre mais atenta e consegui falar claramente sobre esse assunto com meus filhos.

Professora I: O curso proporcionou um maior conhecimento sobre a temática, facilitando assim a conversa sobre sexualidade com as crianças de uma forma mais prática e simples, respeitando as peculiaridade e especificidades de cada uma, contribuindo também no atendimento às famílias quando necessário. 
Professora J: Sempre que a oportunidade surge, procuro desmistificar alguns conceitos tão impregnados no "imaginário" dos alunos.

As formações continuadas proporcionaram a professores e professoras um olhar mais naturalizado e menos conflituoso aos assuntos relacionados a sexualidade, levando a mudanças pessoais e profissionais. Dessa forma, o trabalho com as manifestações relacionadas a sexualidade tornam-se parte de suas práticas pedagógicas sem espanto, vergonhas ou insegurança em responder, explicar e discutir o assunto.

Figueiró (2014: 32) afirma que, "envolver-se em um processo de formação continuada, embasado na prática reflexiva, auxilia o professor em seu desenvolvimento profissional e na melhoria de sua prática pedagógica”. Dessa forma, essas formações aumentariam a possibilidade, a frequência e a desenvoltura dos profissionais em trabalharem com o tema. De acordo com estudo realizado por Figueiró (2014), professores e professoras veem nas formações continuadas a possibilidade de conquistar crescimento e valorização profissional, além de exercer influência no ambiente de trabalho, auxiliando e motivando os demais colegas a trabalharem com a temática sexualidade. As respostas obtidas em nosso estudo vêm ao encontro dessa afirmação, pois, quando questionados se participariam de novas formações continuadas sobre a temática os/as participantes responderam afirmativamente.

A Educação Sexual "deve integrar o conhecimento popular e o científico, pois, igualmente válidos, ambos constituem as experiências dos sujeitos e expressam a variedade sociocultural humana" (Furlani, 2009: 46). Nossa sexualidade é influenciada pelo meio no qual estamos inseridos, e dessa forma, devemos considerar os conhecimentos trazidos por nossos alunos e alunas, agregando a este saber o conhecimento científico, a fim de ampliar e desmistificar os medos, dúvidas ou vergonhas que existam a respeito do assunto. Segundo Figueiró (2014: 44), "a Educação Sexual deve abranger tanto o componente informativo quanto o formativo". É preciso considerar as experiências, conhecimentos do indivíduo, acrescentando a estas informações e saberes novos, promovendo dessa forma sua formação críticoreflexiva sobre sexualidade. A Educação Sexual deve promover transformações tanto nos relacionamentos sexuais quanto sociais, incentivando a autonomia de viver a sexualidade e a confiança em delatar situações repressoras (Figueiró, 2014). É por meio desta que podemos desfazer os conceitos e valores da heteronormatividade impostos em nossa sociedade.

A educação pode promover transformações sociais, como a diminuição do preconceito, das violências físicas e/ou psicológicas, motivar o respeito, a tolerância e aceitação das diversidades que existem em nossa sociedade. "As formas de viver a sexualidade, experimentar prazeres e desejos, precisam ser compreendidas como problemas ou questões da sociedade e da cultura e não apenas do indivíduo" (Louro, 
2007: 204). É preciso aceitar e compreender as diferentes formas de vivenciar a sexualidade, parte integrante e inseparável do indivíduo.

\section{Considerações finais}

Analisar a importância da abordagem da sexualidade na formação continuada de professores e professores nos proporcionou conhecer as necessidades, dificuldades e dúvidas dos professores e professoras em relação a discussão, abordagem e reflexão destes assuntos em sala de aula. É comum esses e essas profissionais se pautarem na deficiência da formação inicial, na falta de apoio de gestores e familiares como principais motivos e obstáculos para a não abordagem da temática. As formações continuadas surgem como possibilidade de mudanças de posturas pessoais e profissionais para o trabalho com Educação Sexual na escola.

Os resultados do estudo apontaram para a necessidade de formação inicial e continuada que oportunizem a esses profissionais o conhecimento e (in) formação sobre sexualidade para que possam incorporar na sua prática pedagógica está abordagem. As formações continuadas podem ser vistas como um meio para colocar em movimento os imaginários da sexualidade, muitas vezes cristalizados, promovendo reflexões, discussões proporcionando assim novas práticas pedagógicas.

Acreditando que as formações continuadas são uma ferramenta de auxílio para o trabalho sobre sexualidade, é necessário promover um quantitativo maior de formações. Assim, mais profissionais terão acesso a estas e conseguirão inserir em suas práticas a Educação Sexual. Enfim, este estudo evidenciou a importância e a necessidade de uma Educação Sexual na escola que promova o respeito e o conhecimento do indivíduo como um todo, ou seja, uma educação que prime por qualidade, respeito e a afetividade das relações sociais. Uma Educação Sexual que discuta e reflita sobre diversidade de gênero, preconceitos, violências sexuais, discriminações, entre outros. Entretanto, é indispensável além da formação inicial e continuada de professores e professoras, o envolvimento da família, gestores, equipe pedagógica e da comunidade escolar em geral.

\section{Agradecimentos}

À Fundação Araucária pela bolsa de Iniciação Científica (PIBIC 03/2016), a Universidade Estadual do Oeste do Paraná (Unioeste) e ao Grupo de Pesquisa sobre Sexualidade e Educação (GEPEX) pelo provimento do espaço e condições para a realização do trabalho. 


\section{Referências}

AQUINO, Julio Groppa; MUSSI, Mônica Cristina. (2001). As vicissitudes da formação docente em serviço: a proposta reflexiva em debate. Educação e Pesquisa, n. 27, 2: p. 211-227, jul-dez.

BONFIM, Cláudia. (2010). Educação Sexual e formação de professores: da educação sexual que temos à educação que queremos. 1a edição. João Pessoa-PB: UFPB.

BRITTOS, Eritânia Silmara de; SANTOS, Aline Bruna dos; GAGLIOTTO, Giseli Monteiro. (2013). "A importância da Educação Sexual na formação de professores: o projeto laboratório de educação sexual adolescer e a intervenção necessária junto aos adolescentes no espaço escolar". In: SIMPÓSIO INTERNACIONAL DE EDUCAÇÃO SEXUAL, 3, Maringá-PR. Anais do... Maringá-PR: SIES, p. 1-16. Disponível em: <goo. gl/nsHND2>. Acesso em: 20 set. 2017.

FAGUNDES, Tereza Cristina Pereira Carvalho. (2014). Sexualidade, gênero e poder: educação numa perspectiva emancipatória. Revista Espaço Acadêmico, n. 154: p. 1-17, mar.

FERRARI, Alexandre Sebastiao; MARTELLI, Andréa Cristina. (2013). Formação de professores, Educação Sexual e PCNs: um olhar. In: MANCHOPE, Elenita Conegero Pastor; FIQUEIREDO, Ireni Marilene Zago; BUSSE, Sanimar. Ação e reflexão: a prática de ensino e seu espaço do fazer pedagógico nos cursos de licenciatura. 1a edição. Cascavel-PR: Gráfica Imprecolor. p. 62-73.

FIGUEIRÓ, Mary Neide Damico. (1996). Educação Sexual: problemas de conceituação e terminologias básicas adotadas na produção acadêmico-científica brasileira. Semina: Ciências Sociais/Humanas. n. 17, 3: p. 286-293, set.

FIGUEIRÓ, Mary Neide Damico. (2000). A viabilidade dos temas transversais à luz da questão do trabalho docente. Revista de Psicologia Social e Institucional. n. 2, 1: p. 1-17, jun.

FIGUEIRÓ, Mary Neide Damico. (2006). Educação Sexual: como ensinar no espaço da escola. Revista Linhas. n. 7, 1: p. 1-21.

FIGUEIRÓ, Mary Neide Damico. (2011). Educação Sexual: retomando uma proposta, um desafio. za edição. Londrina-PR: Eduel.

FIGUEIRÓ, Mary Neide Damico. (2014). Formação de Educadores Sexuais: adiar não é mais possível. 2a edição. Londrina-PR: Eduel. 
FLORES, Ainda Mair Prado. (2004). Sexualidade: representações de professores do Ensino Médio. Dissertação (Mestrado em Educação) - Programa de Pós-Graduação em Educação, Universidade Federal de Santa Maria, Santa Maria-RS, mimeo.

FURLANI, Jimena. (2009). "Encarar o desafio da educação sexual na escola”. In: PARANÁ. Secretaria de Estado da Educação. Sexualidade. 1a edição. Curitiba-PR: SEED, p. 37-48.

GADOTTI, Moacir. (2003). Boniteza de um sonho: ensinar e aprender com sentido. 1a edição. São Paulo-SP: GRUBHAS.

GESSER, Marivete; OLTRAMARI, Leandro Castro; CORD, Denise; NUERNBERG, Adriano Henrique. (2012). Psicologia escolar e formação continuada de professores em gênero e sexualidade. Psicologia Escolar e Educacional, n. 16, 2: p. 229-236, juldez.

GUIMARÃES, Isaura Rocha Figueiredo. (1995). Educação Sexual na escola: mito e realidade. 1a edição Campinas-SP: Mercado de Letras.

JARDIM, Dulcilene Pereira; BRÊTAS, José Roberto da Silva. (2006). Orientação sexual na escola: a concepção dos professores de Jandira - SP. Revista Brasileira de Enfermagem, n. 59, 2: p. 157-162, mar-abr.

JESUS, Railda Maria Bispo de. (2007). Implicações da ação docente sobre questões de sexualidade e gênero na escola. Revista Faced, n. 11: p. 189-199, jan-jun.

LEÃO, Andreza Marques de Castro; RIBEIRO, Paulo Rennes Marçal; BEDIN, Regina Celia. (2010). Sexualidade e orientação sexual na escola em foco: algumas reflexões sobre a formação de professores. Revista do Programa de Pós-Graduação em Educação, n. 11, 1: p. 36-52, jun.

LOURO, Guacira Lopes. (2001). Teoria Queer: uma política pós-identitária para a educação. Revista Estudos Feministas. n. 9: p. 541-553, jun-dez.

LOURO, Guacira Lopes. (2007). Gênero, sexualidade e educação: das afinidades políticas às tensões. Educar em Revista, n. 46: p. 201-218, dez.

LOURO, Guacira Lopes; WEEKS, Jeffrey; BRITZMAN, Deborah; HOOKS, Bell: PARKER, Richard; BUTLER, Judith. (2000). O corpo educado: Pedagogias da sexualidade. za edição. Belo Horizonte-MG: Autêntica.

MACEDO, Senei da Rocha Henrique; MIRANDA, Francisco Arnoldo Nunes de; PESSOA-JÚNIOR, João Mário; NÓBREGA, Vannucia Karla de Medeiros. (2013). 
Adolescência e sexualidade: scripts sexuais a partir das representações sociais. Revista Brasileira de Enfermagem, n. 66, 1: p. 103-109, jan-fev.

MEYER, Dagmar Elisabeth Estermann; KLEIN, Carin; ANDRADE, Sandra dos Santos. (2009). "Sexualidade, prazeres e vulnerabilidade: questões para a educação escolar". In: PARANÁ. Secretaria de Estado da Educação. Sexualidade. 1a edição. Curitiba-PR: SEED, p. 81-89.

MOIZÉS, Julieta Seixas; BUENO, Sonia Maria Villela. (2010). Compreensão sobre sexualidade e sexo nas escolas segundo professores do ensino fundamental. Revista Escola Enfermagem. n. 44, 1: p. 205-212, mar.

OLIVEIRA, Maria Marly de. (2016). Como fazer pesquisa qualitativa. 7a edição. Petrópolis-RJ: Vozes.

RIBEIRO, Paula Regina Costa; MAGALHÃES, Joanalira Corpes. (2017). Debates contemporâneos sobre educação para a sexualidade. 1a edição. Rio Grande-RS: Editora da FUR.

ROHDEN, Fabíola. (2009). Gênero, sexualidade e raça/etnia: desafios transversais na formação do professor. Cadernos de Pesquisa, n. 39, 136: p. 157-174, jan-abr.

SANTOS, Dayana Brunetto Carlin dos; ARAUJO, Débora Cristina de. (2009). Sexualidades e gêneros: questões introdutórias. In: PARANÁ. Secretaria de Estado da Educação. Sexualidade. 1a edição. Curitiba-PR: SEED. p. 13-27.

Recebido: 27.09.2017

Aceito: 07.05.2018 